\title{
The assessment of nutrient loading and retention in the upper segment of the Chinyika River, Harare: Implications for eutrophication control
}

\author{
Taurai Bere \\ Department of Biological Science, University of Zimbabwe, MP 167 Mt Pleasant, Harare, Zimbabwe
}

\begin{abstract}
The nutrient loading and retention in the upper catchment of the Chinyika River were assessed during the period October 2004 to February 2005. The river flow variables and water samples were collected monthly at 8 sampling stations along the river. The samples were analysed for concentrations of total nitrogen and total phosphorus, that when multiplied with river flow discharge, translates into nutrient loads. The nutrient loads were high below the sewage outflow generally decreasing with increasing distance from that point because of nutrient retention. The nutrient loads were high during the wet months compared to the dry months suggesting that organic matter was washed away from diffuse sources in the catchment into the river. The nutrients from the sewage effluent discharge and other diffuse sources in the catchment were retained over a distance of about $4 \mathrm{~km}$ from the point of sewage outflow. High natural nutrient retention capacity of rivers ensures that the problem of wastewater disposal and diffuse pollution does not lead to eutrophication of downstream lakes and reservoirs. Management of the nutrient retention capacity of rivers is, therefore, central to sound watershed management practices.
\end{abstract}

Keywords: nutrient, load, retention, eutrophication

\section{Introduction}

Under natural conditions, riverine cycles of nutrients are intricately woven into the overall balance of the riparian ecosystem (McClain et al., 1998). However, an excessive supply of nutrients (eutrophication), usually human-induced, disrupts the natural functioning of these systems (Bartram and Ballance, 1996; Hanrahan et al., 2001; Morrison et al., 2001; Bourne et al., 2002).

Nitrogen and phosphorus enter rivers through several hydrological, geological and biological pathways depending on the natural and anthropogenic processes taking place in the catchment (McClain et al., 1998; Wassman and Olli, 2004). These processes are generally known from numerous studies of small catchments as well as from recent global- and continental-scale assessments of nutrient sources (Howarth et al., 1996; Jordan and Weller, 1996; Carpenter et al., 1998).

The total quantity of nutrients discharged into surface waters in a river basin is normally larger than the nutrient load at the river mouth (Wassman and Olli, 2004). This discrepancy can be explained by the process of nutrient retention, which is a collective expression for a large number of biogeochemical and hydrological processes that temporarily decrease, decay, degrade, transform, or permanently retard and remove the substance from the river channel.

This nutrient-retention process is very effective and the system will suffer no permanent damage as long as its capacity has not been exceeded (Spellman, 1996). If this capacity is exceeded the system will become ecologically stressed with the symptoms of eutrophication becoming increasingly obvious and extensive.

+263912 944 922; fax: +263 4 303211;

e-mail: taubere@yahoo.com

Received 25 September 2006; accepted in revised form 24 January 2007.
An understanding of the nutrient retention process is therefore important to prevent overloading the system and the resultant eutrophication (Nhapi et al., 2001). The present study was carried out in an attempt to assess nutrient loading in and the natural capacity of the Chinyika, a tributary of the Mazowe River, to retain nutrients from sewage disposal as well as other sources in the catchment with reference to its implications on eutrophication.

\section{Study area}

The location of the study area and sampling points is shown in Fig. 1. The area can be divided into two sections depending on the anthropogenic activities taking place. To the east of the road, where most settlements (formal and informal) are located, all vacant land is heavily cultivated by individuals who have established gardens close to the river and cleared most of the riparian vegetation. A small wetland, which is too wet for cultivation, occurs behind the road and supports a dense population of Typha capensis.

Two small commercial farms are located to the west of the road and each has a small dam. The first farm is primarily a crop producer and lacks cattle; because of this, the upper impoundment supports dense marginal vegetation consisting of Typha capensis, while its open water is densely covered by Hydrocotyle spp. and Lemna spp. The second farm produces chickens and has large numbers of cattle that have destroyed the marginal vegetation around the lower dam. The dam is surrounded by dense growth of Typha capensis while its open water is densely and almost completely covered by Ceratophyllum spp. Further downstream, there are at least eight registered water users who abstract water from the Chinyika River (Manyembere, 2005), and the possibility that effluents from Hatcliffe Township now pollute the river is a matter of concern. 


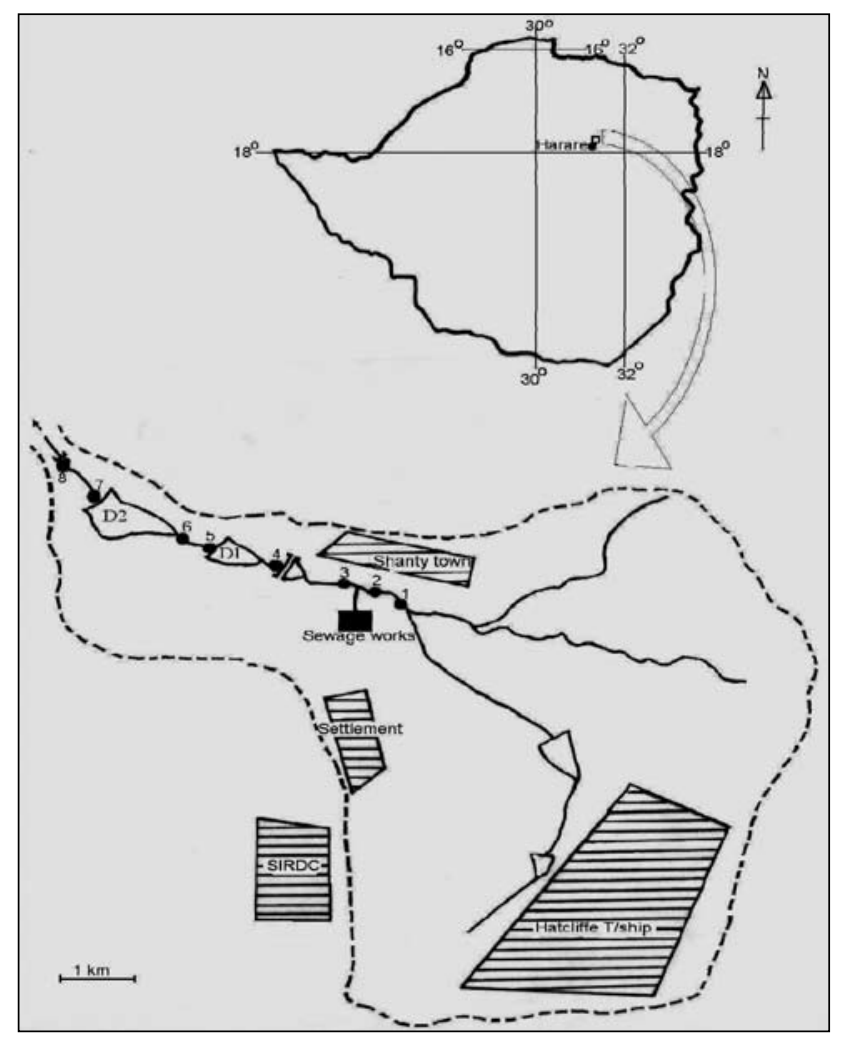

Figure 1

The location of the upper Chinyika River Basin showing the location of sampling stations and human settlements (D1 = dam 1; D2 = dam 2 and wt = wetland $)$

\section{Materials and methods}

\section{Data collection}

A total of eight sampling stations were established along the river (Fig. 1). Stations 1 and 2 were located above the outflow from Hatcliffe Sewage Works and were intended to be reference points showing the condition of the river before sewage discharge. Both sites were open to contamination from other sources such as accidental discharges from blocked manholes and diffuse pollution from agricultural activities taking place in the catchment. Station 3 was located below the sewage outflow to detect the effect of effluent from clarifiers as well as sludge from drying beds that occasionally spill into the river. Station 4 was at the outflow from the artificial wetland created as a result of road construction while Station 5 was located on the outflow of the upper impoundment (D 1). Station 6 was on the inlet of the lower impoundment (D 2) and Station 7 was on the outflow from this impoundment. The last station (Station 8) was about $700 \mathrm{~m}$ downstream from the second impoundment.

Water samples for chemical analysis were collected each month from October 2004 to February 2005. Before sampling the sample bottles were cleaned by soaking in a detergent for $24 \mathrm{~h}$, followed by rinsing with tap water until they were free of detergent. They were then soaked in $5 \%$ nitric acid overnight and then rinsed with distilled water. In the field the bottles were rinsed three times with water at the sampling station before the sample was collected, care being taken to throw the rinsed water downstream of the point where the sample was to be collected.
At each sampling point, three water samples were collected within a distance of $5 \mathrm{~m}$ of each other and tightly sealed, labelled with date, time and station number and taken to the laboratory for analysis. No preservatives were added to the samples before analysis but they were refrigerated within $12 \mathrm{~h}$ of collection.

The current velocity was measured monthly at each station with an FP 201 global flow probe. The width of the stream at each station was measured with a tape measure stretched across the stream. Depth was measured with a staff gauge across a transect at intervals that were determined by the cross section of the river, being closely spaced where it was irregular or where there was a rapid change in velocity and more widely spaced in the centre of the stream where the flow was uniform.

\section{Laboratory analysis}

The cross-sectional view of each station was plotted on graph paper using the width and depth measurements obtained in the field to obtain cross-sectional area of flow. The discharge at each station was then estimated by the velocity area method using the relation:

$$
\mathrm{Q}=\mathrm{VA}
$$

where:

$$
\begin{aligned}
Q & =\text { discharge }\left(\mathrm{m}^{3} \mathrm{~s}^{-1}\right) \\
V & =\text { mean velocity }\left(\mathrm{m} \cdot \mathrm{s}^{-1}\right) \\
A & =\text { area of cross-section }\left(\mathrm{m}^{2}\right)(\text { Schumm, 1977) }
\end{aligned}
$$

The concentration of total nitrogen was determined with a Hach DR/2010 spectrophotometer using the persulphate digestion method in which heated alkaline persulphate converts all forms of nitrogen to nitrate. Sodium metabisulphite is added after the digestion to eliminate halide interferences. Nitrate then reacts with chromotropic acid under strongly acidic conditions to form a yellow complex with an absorbance maximum at $410 \mathrm{~nm}$. This method generally yields $95-100 \%( \pm 2 \%)$ recovery of nitrogen (Hach Company, 1996-2000).

The concentration of total nitrogen was also determined with a Hach DR/2010 spectrophotometer using the high range acid digestion method. Pretreatment of the samples with acid persulphate and heat provide conditions for hydrolysis of condensed inorganic and organic forms of phosphates to form reactive orthophosphate that reacts with molybdate in an acid medium to produce a phosphomolybdate complex. In the presence of vanadium, yellow vanadomolybdophosphoric acid form. The intensity of the yellow colour is proportional to the phosphate concentration (Hach Company, 1996-2000).

The concentrations of total nitrogen and total phosphorus were then used to estimate the nutrient load in the water at a given time at each station since the nutrient load is the product of concentration and discharge, as follows:

$\mathrm{L}=\mathrm{QC}$ where:

$$
\begin{aligned}
& L=\text { nutrient load }\left(\mathrm{g} \cdot \mathrm{s}^{-1}\right) \\
& Q=\text { discharge }\left(\mathrm{m}^{3} \cdot \mathrm{s}^{-1}\right) \\
& C=\text { concentration }\left(\mathrm{g} \cdot \mathrm{m}^{-3}\right)(\text { Bourne et al., 2002) }
\end{aligned}
$$

The degree of nutrient retention that took place between stations was calculated as follows:

$$
\begin{array}{ll}
\begin{array}{c}
N_{m}= \\
\text { where: }
\end{array} & \left(L_{1}-L_{2}\right) \\
N_{m}= & \text { nutrient retention capacity }\left(\mathrm{g} \cdot \mathrm{s}^{-1}\right) \\
L_{1} \text { and } L_{2}= & \text { nutrient load }\left(\mathrm{g} \cdot \mathrm{s}^{-1}\right) \text { at the upstream and down- } \\
& \text { stream stations respectively (Bourne et al., 2002) }
\end{array}
$$




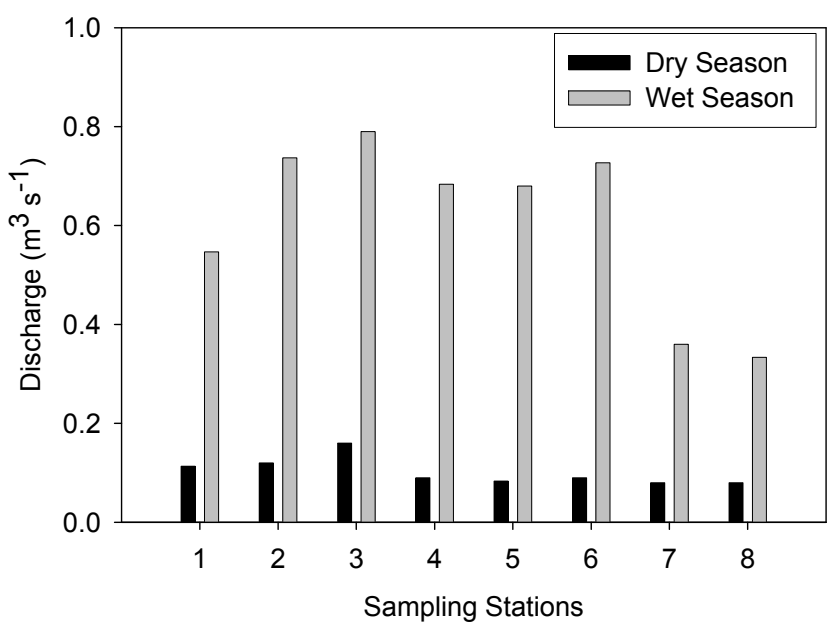

Figure 2

The mean discharge of the Chinyika River at Station 8 during the dry months and wet months. December was included in the calculation of mean monthly discharge for dry and wet months in this and other subsequent figures and tables since it marked the end of the dry season as well as the beginning of the wet season.

\section{Results}

\section{Discharge}

This investigation began in the late dry season (October 2004) and continued into the peak of the rains in January up to February (2005), which meant that there was considerable variation in the flow of the upper Chinyika River (Fig. 2). The highest discharge generally occurred at Station 3 just below sewage outflow with the lowest at Station 8 suggesting that the two small dams were retaining water and reducing downstream flow.

\section{Nitrogen loading and retention}

The loading of nitrogen was high during the wet months compared to the dry months (Fig. 3). This pattern is similar to that of discharge (Fig. 2) suggesting that organic and inorganic matter was washed from the catchment to the river channel resulting in the high nutrient loads. High loading was generally recorded at Station 3, just after the sewage outflow and the lowest loading was recorded at the last (Station 8) suggesting that the nutrients had been retained between these two stations.

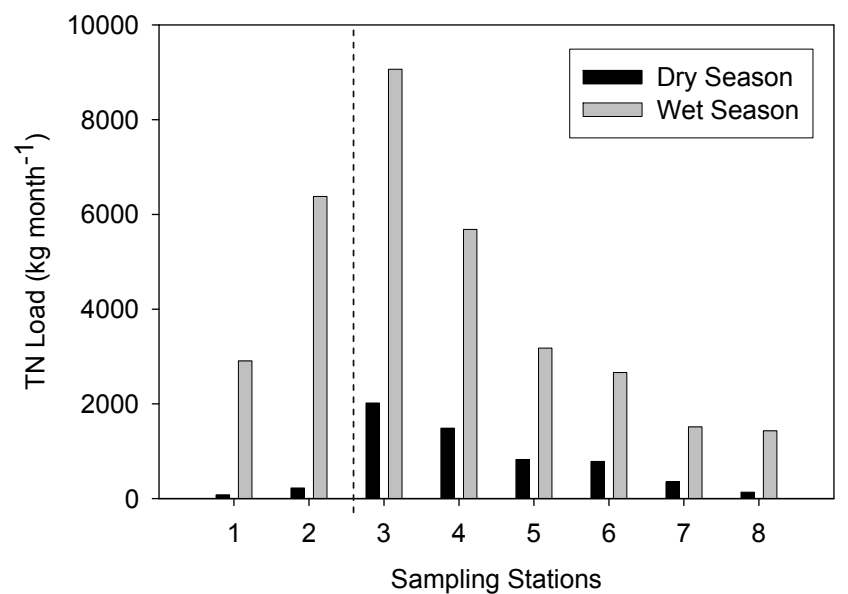

Figure 3

The total nitrogen loads recorded at each station for dry and wet months. The broken vertical line in this and subsequent figures denotes the position of the sewage outflow.

The quantity of total nitrogen that was retained by the different sections of the river is shown in Table 1. During the wet months some sections of the river acted as sources of nutrients instead of sinks resulting in negative nutrient retention values (Table 1). This suggests that previously retained nitrogen may have been re-suspended during storms or extra nutrients were coming from other sources in the sub-catchments. This also coincided with the disintegration of the wetland through the senescence of its vegetation suggesting that a reduced uptake of nutrients by plants contributed to reduced nutrient retention.

\section{Phosphorus loading and retention}

The pattern for total phosphorus loading was very similar to that of total nitrogen loading. The loading was directly proportional to discharge (Fig. 2) being high during the wet months possibly because of a lot of organic matter and soil that was being washed away from the catchment by runoff into the river (Fig. 4). The highest loading was generally recorded at Station 3 just after sewage outflow as expected and lowest levels were recorded at the last station suggesting phosphorus retention between the two stations both during the dry and wet months.

The quantity of total phosphorus that was retained by different sections of the river is shown in Table 2. During the wet months, an average of $1242 \mathrm{~kg} \cdot \mathrm{month}^{-1}$ of total phosphorus came

\begin{tabular}{|l|c|c|c|c|c|}
\hline $\begin{array}{l}\text { TABLE 1 } \\
\text { The quantity of total nitrogen (kg· } \text { month }^{-1} \text { ) retained in different } \\
\text { sections of the Chinyika River downstream of the sewage outflow }\end{array}$ \\
\hline & & \multicolumn{5}{|c|}{ Stretches between stations } \\
\hline & $\mathbf{3 ~ \& ~ 4}$ & $\mathbf{4 ~ \& ~ 5 ~}$ & $\mathbf{5 ~ \& ~ 6}$ & $\mathbf{6 ~ \& ~ 7}$ & $\mathbf{7 ~ \& ~ 8}$ \\
\hline October & 937 & 295 & 54 & 187 & 268 \\
\hline November & 1244 & 415 & 415 & 700 & 334 \\
\hline December & -589 & 1286 & -348 & 402 & 54 \\
\hline January & 9455 & 6535 & 1125 & 3241 & -214 \\
\hline February & 1282 & -315 & 774 & -194 & 411 \\
\hline Mean for dry months & 531 & 665 & 40 & 430 & 219 \\
\hline Mean for wet months & 3383 & 2502 & 517 & 1150 & 84 \\
\hline
\end{tabular}




\begin{tabular}{|c|c|c|c|c|c|}
\hline \multicolumn{6}{|c|}{$\begin{array}{l}\text { TABLE } 2 \\
\text { The quantity of total phosphorus }\left(\mathrm{kg} \cdot \text { month }^{-1}\right) \text { (nutrient retention } \\
\text { capacity) retained in different sections of the Chinyika River down- } \\
\text { stream of the sewage outflow }\end{array}$} \\
\hline & \multirow[b]{2}{*}{$3 \& 4$} & \multicolumn{4}{|c|}{ Stretches between stations } \\
\hline & & $4 \& 5$ & $5 \& 6$ & $6 \& 7$ & $7 \& 8$ \\
\hline October & 991 & 428 & 482 & 0 & 16 \\
\hline November & 1555 & 130 & 337 & 570 & 44 \\
\hline December & 134 & 268 & 27 & 134 & 134 \\
\hline January & 1526 & -750 & 455 & 1848 & 455 \\
\hline February & -1597 & 1718 & 121 & -24 & 24 \\
\hline Mean for dry months & 893 & 275 & 282 & 235 & 65 \\
\hline Mean for wet months & 21 & 412 & 201 & 653 & 204 \\
\hline
\end{tabular}

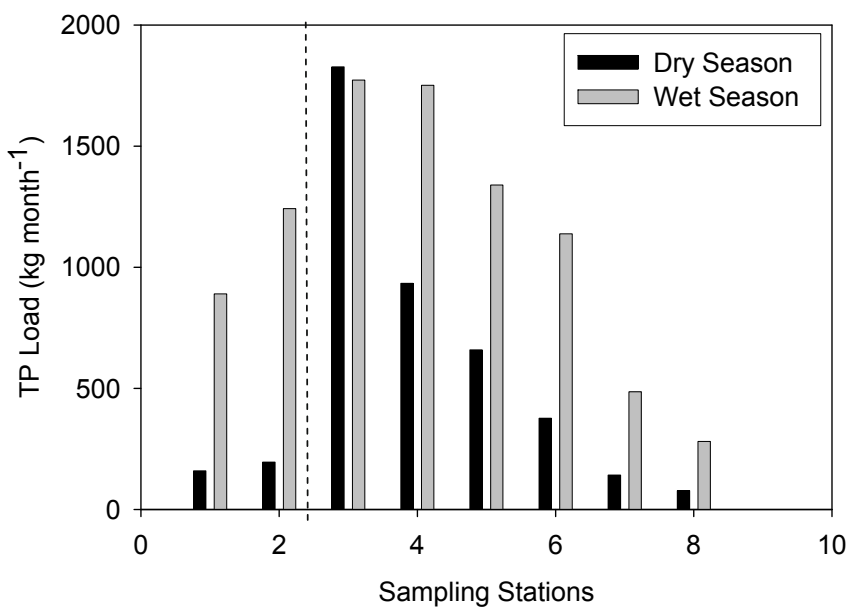

Figure 4

The total nitrogen loads recorded at each station for dry and wet months

from the catchment above the sewage outflow, and $531 \mathrm{~kg} \cdot \mathrm{month}^{-1}$ was added by the sewage works. The section between the sewage outflow and Station 4 just after the first wetland retained $21 \mathrm{~kg} \cdot \mathrm{month}^{-1}$, a value that is lower than the one obtained during the dry season $\left(893 \mathrm{~kg} \cdot \mathrm{month}^{-1}\right)$ possibly because of reduced residence time of the water and reduced sedimentation, which is the main process of phosphorus retention in wetlands. This also suggests that previously retained phosphorus was flushed away during storms and this section acted as source rather than a sink as in February where negative nutrient retention was recorded (Table 2). The low nutrient retention capacity could also be attributed to wetland disintegration through vegetation senescence during this period, suggesting reduced nutrient uptake by plants. This was probably true for all the other sections where negative nutrient retention amounts were recorded.

\section{Discussion}

The nutrient retention process in upper Chinyika River can result in nutrient loads similar to those of the stream above the sewage works over a distance of about $4 \mathrm{~km}$ from the point of sewage outflow. This is very important as it guards against water quality deterioration in downstream impoundments such as the Mazowe Dam. Since the effluent of some towns becomes the water supplies of the other settlements downstream (Mason,
1981), this study is very important for downstream water users who may use the river water as source of their domestic water. This is often the case in Zimbabwe since a large part of the rural population relies on river water. Working towards protecting and improving the upper Chinyika River system's nutrient retention capacity should therefore be considered as a complement to other programmes and efforts to protect water quality.

High nutrient retention capacity occurs in the section of the river whose riparian wetlands have been greatly modified by stream-bank and stream-bed cultivation and cattle grazing. What if riparian wetlands could be restored and monitored? This will dramatically improve the nutrient retention capacity of the system as demonstrated by numerous studies from other similar systems (Magadza and Masendu, 1986; Barbier et al., 1997; Machena, 1997; Marshall, 1997). The proper construction, design, monitoring and maintenance of the effectiveness of the riparian wetlands along the Chinyika River and other rivers in Zimbabwe, therefore, holds great potential as cheap and environmentally friendly technology for enhancing riverine nutrient retention and hence control of eutrophication.

A small wetland (about 1.5 ha) between Stations 3 and 4, that could not be cultivated because it is very wet, appeared to retain a lot of nutrients annually. Like other wetlands, however, its retention capacity is finite and as Hatcliffe Township continues to grow, a point will be reached where the wetland can no longer cope with nutrients in sewage effluent and this is likely to have an impact on downstream water users. The situation is likely to be further complicated in future by the predicted high frequency with unpredictable occurrence and distribution of extreme weather events such as severe rain storms, droughts, and severe winter spells that are likely to affect the water quality of rivers (IUCN, 2003).

As a way of ensuring the continued functioning and better service provision by this wetland, its area should be increased so as to increase the time and area over which biological, physical and chemical processes operate. This can be achieved by banning urban agriculture, which has been the policy of the government for years but its implementation remains to be seen. The other option for increasing the wetland area is to raise the walls of the bridge at Station 4 by say $0.5 \mathrm{~m}$ and this is likely to double the area covered by the wetland because of the flatness of the terrain.

The other option of maintaining or improving nutrient retention in the Chinyika River amidst future threats on water quality is to construct more impoundments. The two small impound- 
ments currently in this system greatly enhance the nutrient retention capacity of the Chinyika River. The construction of more impoundments downstream is likely to improve the nutrient retention capacity of the river and should be an option worth considering by local authorities to safeguard downstream water quality.

The nutrient retention capacity was low in February because of riparian vegetation senescence. The nutrients previously locked up in plant matter were released back into the system as the vegetation decayed. The permanent removal of nutrients locked up in vegetation from the system can be achieved through vegetation harvesting (Nhapi and Tirivarombo, 2004; Zimmels et al., 2004)

The nutrient loading increased with increasing discharge, probably because of organic and inorganic matter washed from diffuse sources in the catchment, supplying sufficient nutrients to maintain a eutrophic state in the system. The ZINWA effluent standards, which form the basis of the present pollution control activities in Zimbabwe, provide no framework for control of non-point sources of pollution such as stormwater runoff in this case. These guidelines, therefore, cannot guarantee that quality objectives in receiving waters will continue to be met (Gumbo, 1997). A closer examination of these guidelines is thus called for so that diffuse pollution is factored in, but this is admittedly difficult and costly.

Several management options may be considered to reduce the impact of stormwater runoff on receiving water bodies such as routing of stormwater through wastewater treatment works, creation and maintenance of riparian wetlands, or the combination of the above (Thornton and Nduku, 1981). The first option is expensive as it involves the construction of additional sewer mains and expansion of wastewater treatment facilities used, under Zimbabwean conditions, only for a fraction of a year. The second option has been the policy of the government for years and this study has shown the important role played by riparian wetlands in stormwater reclamation. The protection of the riparian wetlands in the upper Chinyika River, therefore, constitutes a promising water quality control measure worth considering by the local government.

The nutrient retention capacity of the upper Chinyika River has been successfully quantified. This enables ascribing economic value to the system to be made (Constanza et al., 1997) which gives ecosystem services more weight in policy decision. This gives ecosystems a legitimate place when considering options for water quality management. The restoration of riparian wetlands and design of shallow impoundments on tributaries of reservoirs such as Lake Chivero for management of water quality in the system is thus recommended. The harnessing of the natural nutrient retention process in constructed wetlands where optimum conditions can be maintained for treatment of municipal wastewater is also an option worth considering by local authorities.

\section{Acknowledgements}

This study was made possible by funding from the Government of Belgium through the University of Zimbabwe/Flemish Universities link (Aquatic Ecology Project). I am greatly indebted to Professor Brian Marshall (previously at the University of Zimbabwe and now at Lake Victoria Fisheries, Jinja, Uganda) for his critical remarks on earlier drafts of this paper. I also wish to thank all my friends for their support during the course of this study.

\section{References}

BARBIER EB, ACREMAN N and KNOWLER D (1997) Economic Valuation of Wetlands. A Guide for Policy Makers and Planners. RAMSAR Convention Bureau, Gland, Switzerland.

BARTRAM J and BALANCE R (1996) Water Quality Monitoring: A Practical Guide to Design and Implementation of Freshwater Quality Studies and Monitoring Programmes. Chapman and Hall, London.

BOURNE A, ARMSTRONG N and JONES G (2002) A Preliminary Estimate of Total Nitrogen and Total Phosphorus Loading to Streams in Manitoba, Canada. Manitoba Conservation Report No. 2002-04.

CARPENTER SR, CARACO NF, CORRELL DL, HOWARTH RW, SHARPLEY AN and SMITH VH (1998) Non-point pollution of surface waters with phosphorus and nitrogen. Ecol. Applic. 8 559-568.

CONSTANZA R, d'ARGE R, de GROOT R, FARBER S, GRASSO M, HANNON B, LIMBURG K, NAEEM S, O'NEILL RV, PARUELO J, RASKIN RG, SUTTON P and van den BELT M (1997) The value of the world's ecosystem services and natural capital. Nature $\mathbf{3 8 7}$ 253-260.

GUMBO B (1997) Integrated water quality management in Harare. Proc. $23^{r d}$ WEDC Conference on Water and Sanitation for All: Partnerships and Innovations. 1-2 November, Durban, South Africa.

HACH COMPANY (1996-2000) DR/2010 Spectrophotometer Handbook. U.S.A.

HANRAHAN G, GLEDHILL M, HOUSE WA and WORSFOLD PJ (2001) Phosphorus loading in the Frome Catchment, UK: seasonal refinement of the coefficient modelling approach. J. Environ. Qual. 30 1738-1746.

HOWARTH RW, MARINO R and LANE J (1996) Regional nitrogen budgets and riparian $\mathrm{N}$ and $\mathrm{P}$ fluxes from drainages to the Northern Atlantic Ocean: Natural and human influence. Biogeochem. 35 75139.

IUCN-THE WORLD CONSERVATION UNION (2003) Climate Change, Water and Wetlands in Southern Africa; A Discussion Paper for a Regional Dialogue. IUCU-The World Conservation Union, Regional Office for Southern Africa.

JORDAN TE and WELLER DE (1996) Human contributions to terrestrial nitrogen fluxes: assessing the sources and fates of anthropogenic fixed nitrogen. Biosci. 46 655-664.

MACHENA C (1997) The pollution and self-purification capacity of the Mukuvisi River. In: Moyo NAG (ed.) Lake Chivero: A Polluted Lake. University of Zimbabwe Publishers, Harare, Zimbabwe. pp 75-91.

MAGADZA CHD and MASENDU H (1986) Some observations in mine effluent in the Yellow Jacket stream, Zimbabwe. Zimbabwe Sci. News 20 11-28.

MAMYEMBERE G (2005) Personal Communication. Mazowe Catchment Office, Harare, Zimbabwe.

MARSHALL BE (1997) Lake Chivero after forty years: The impact of eutrophication. In: Moyo NAG (ed.) Lake Chivero: A Polluted Lake. University of Zimbabwe Publishers, Harare, Zimbabwe. 1-12.

MASON CF (1981) Biology of Freshwater Pollution. Longman, London.

McCLAIN ME, BILBY RE and TRISKA FJ (1998) Biogeochemistry of $\mathrm{N}, \mathrm{P}$, and $\mathrm{S}$ in Northwest Rivers: Natural distributions and responses to disturbance. In: Naiman RJ and Bilby RE (eds.) River Ecology and Management: Lessons from the Pacific Coastal Ecoregion. Springer Verlag, New York. 347-372.

MORRISON G, FATOKI OS, PERSSON L and EKBERG A (2001) Assessment of the impact of point source pollution from the Keiskammahoek Sewage Treatment Plant on the Keiskamma River - $\mathrm{pH}$, electrical conductivity, oxygen-demanding substances (COD) and nutrients. Water SA 27 (4) 475-480.

NHAPI I, HOKO Z, SIEBEL MA and GIGZEN HJ (2001) Assessment of the major water and nutrient flows in the Chivero catchment area, Zimbabwe. Proc. ARFSA/WaterNet Symposium: Integrated Water Resources Management: Theory, Practice, Cases. 30-31 October, Cape Town, South Africa.

NHAPI I and TIRIVAROMBO S (2004) Sewage discharge and nutrient levels in Marimba River, Zimbabwe. Water SA 30 (1) 107-113. 
SCHUMM SA (1977) The Fluvial System. John Wiley and Sons, New York.

SPELLMAN FR (1996) Stream Ecology and Self-Purification - An Introduction for Wastewater and Water Specialists. Technomic Publishing Company, Inc, Lanchaster, Pennsylvania, USA.

THORNTON JA and NDUKU WK (1981) Nutrients in runoff from small catchments with varying land usage in Zimbabwe. Trans. Zimbabwe Sci. Assoc. 61 14-26.
WASSMAN P and OLLI K (2004) Drainage Basin Nutrient and Eutrophication: An Integrated Approach. Norwegian College of Fishery Sciences, University of Trosmø, Norway.

ZIMMELS Y, KIRZHNER F and ROITMAN S (2004) Use of naturally growing aquatic plants for wastewater purification. Water Environ. Res.76 220-230. 